\title{
Cancer angiogenesis induced by Kaposi's sarcoma-associated herpesvirus is mediated by EZH2
}

\author{
Meilan He ${ }^{1,4}$, Wei Zhang ${ }^{4}$, Thomas Bakken ${ }^{1}$, Melissa Schutten ${ }^{3,}{ }^{*}$, Zsolt Toth $^{4}$, Jae U. Jung ${ }^{4}$, \\ Parkash Gill $^{5}$, Mark Cannon ${ }^{1,2}$, and Shou-Jiang Gao ${ }^{4}$ \\ ${ }^{1}$ Department of Medicine, The University of Minnesota, Minneapolis, MN, USA \\ ${ }^{2}$ Department of Microbiology, The University of Minnesota, Minneapolis, MN, USA \\ ${ }^{3}$ Department of Veterinary Population Medicine, The University of Minnesota, Minneapolis, MN, \\ USA \\ ${ }^{4}$ Department of Molecular Microbiology and Immunology, University of Southern California Keck \\ School of Medicine, Los Angeles, CA, USA \\ ${ }^{5}$ Department of Medicine, University of Southern California Keck School of Medicine, Los \\ Angeles, CA, USA
}

\section{Abstract}

$\mathrm{EZH} 2$ is a component of the epigenetic regulator PRC2 that suppresses gene expression. Elevated expression of EZH2 is common in human cancers and is associated with tumor progression and poor prognosis. In this study, we demonstrate that EZH2 elevation is associated with epigenetic modifications of Kaposi's sarcoma-associated herpesvirus (KSHV), an oncogenic virus that promotes the development of Kaposi's sarcoma (KS) and other malignancies that occur in patients with chronic HIV infections. KSHV induction of EZH2 expression was essential for KSHVinduced angiogenesis. High expression of EZH2 was observed in KS tumors. In cell culture, latent KSHV infection up-regulated the expression of EZH2 in human endothelial cells through the expression of vFLIP and LANA, two KSHV latent genes that activate the NF- $\mathrm{BB}$ pathway. KSHV-mediated upregulation of EZH2 was required for the induction of Ephrin-B2, an essential pro-angiogenic factor that drives endothelial cell tubule formation. Taken together, our findings indicate that KSHV regulates the host epigenetic modifier EZH2 to promote angiogenesis.

\footnotetext{
Corresponding authors: Shou-Jiang Gao and Meilan He, Department of Molecular Microbiology and Immunology, University of Southern California Keck School of Medicine, 1450 Biggy Street, Los Angeles, CA 90033, USA. shoujiag@ usc.edu; meilan.he@gmail.com, Mark Cannon, Departments of Medicine, The University of Minnesota, Minneapolis, MN, USA. mark.cannon101@gmail.com.

* Current address: Genentech, Inc., 1 DNA Way, South San Francisco, CA 94114, USA

Disclosure of Potential Conflicts of Interest:

No potential conflicts of interest were disclosed.

Authorship

MH designed and performed experiments, analyzed data, and wrote the paper; MS performed IHC; WZ performed RT-qPCR for the Bay-11 study; TB, ZT, JJ, PG contributed reagents, assisted in the infection experiments, and contributed to the writing of the manuscript; MC and SJG directed the project, designed the experiments, analyzed data, and wrote the paper.
} 


\section{Keywords}

KSHV; EZH2; Ephrin-B2; angiogenesis; NF-кB; vFLIP; LANA

\section{Introduction}

Kaposi's sarcoma-associated herpesvirus (KSHV) is the etiologic agent of Kaposi's sarcoma (KS), the most common cancer in HIV-infected subjects. KS is a multifocal neovascular tumor of proliferating spindle endothelial cells latently infected by KSHV (1). In cell culture, KSHV infection converts human primary endothelial cells into spindle-shapes with altered expression of cell surface markers and a distinct cellular gene expression program (2-6). Extensive studies have identified a number of cellular factors that mediate KSHVinduced malignant cellular proliferation (1).

$\mathrm{KS}$ is a highly vascularized and angiogenic tumor. Indeed, KSHV infection promotes the angiogenic phenotypes of endothelial cells, which include induction of tubule formation on Matrigel, capillary morphogenesis in low growth factor conditions, and enhanced migration, invasion and permeability (7-11). Several pro-angiogenic factors are induced following KSHV infeciton of human endothelial cells. These include vascular endothelial growth factor A and C (VEGF-A and -C), angiopoietin-2, IL-6, IL-8, Ephrin-B, MMP-1, MMP-2, and MMP-9 (7, 8, 12-14). Upregulation of these pro-angiogenic cytokines is in part mediated by multiple mitogen-activated protein kinase pathways, Notch pathway, and NF$\mathrm{B}$ pathway $(7,8,12,13,15)$.

Enhancer of Zeste Homolog 2 (EZH2) is a main component of polycomb repressive complex 2 (PRC2), which regulates chromatin structure and gene expression through posttranslational modifications of histone (16). EZH2 has attracted intense interest because of its role in maintaining cell stemness and development of cancer (16). When the PRC2 complex is recruited to chromatin, EZH2 catalyses the trimethylation of the lysine 27 of histone $\mathrm{H} 3$ (H3K27me3), which leads to subsequent recruitment of the PRC1 complex that monoubiquitylates the lysine 119 of histone H2A (H2AK119ub1) to prevent RNA polymerase II-dependent transcriptional elongation leading to transcriptional repression (16, 17). Several reports suggest that EZH2 directly interacts with DNA methyltransferases (DNMT1, DNMT3A, DNMT3B) and that EZH2 is necessary for the maintenance of DNA methylation and repression of specific genes, including tumour suppressor genes $(16,17)$. EZH2 is highly expressed in numerous human cancers, including breast and prostate, with high EZH2 levels often correlating with advanced stages of tumor progression and poor prognosis $(18,19)$. EZH2 connects the estrogen and Wnt signaling pathways by directly interacts with estrogen receptor $a$ and $\beta$-catenin, resulting in transcriptional upregulation of c-myc and cyclin D1 in breast cancer cells (20). Moreover, mutation of EZH2 Y641, which results in gain-of-function, has been described in lymphomas (21). Recent studies have shown that both VEGF and FGF2 induce angiogenesis through up-regulation of EZH2 expression, and inhibition of EZH2 attenuated the cell proliferation, migration and tubule formation of Glioblastoma cells $(18,22-24)$. 
Because of EZH2's important biologic roles in tumorigenesis and angiogenesis, and the results of recent studies that have demonstrated the connection of EZH2 with the epigenetic modifications of the KSHV genome $(25,26)$, we sought to investigate how KSHV infection might regulate $\mathrm{EZH} 2$, and whether such regulation might contribute to KSHV-induced angiogenesis. In the present work, we have found that EZH2 is highly expressed in KS tumors, and KSHV infection of endothelial cells upregulates the expression of EZH2. Furthermore, KSHV up-regulation of EZH2 is partially mediated by the NF- $\mathrm{BB}$ pathway and the viral latent genes vFLIP (ORF71) and LANA (ORF73). Finally, we have shown that EZH2 mediates KSHV-induced endothelial cell tubule formation on Matrigel by regulating the expression of pro-angiogenic gene Ephrin-B2.

\section{Materials and Methods}

\section{Cell lines and reagents}

Uninfected and KSHV-infected SLK cells, named SLKn and SLKp, respectively, were provided by Dr. Adam Grundhoff at Heinrich Pette Institute in September, 2010, and cultured as described (27). The status of KSHV infection was verified in this study (Fig. 2C). Several batches of primary human blood outgrowth endothelial cells (BOEC) were obtained from Dr. Robert Hebbel at the University of Minnesota between 2009 and 2010, and maintained in EGM-2 plus Bullet Kit (Lonza, Walkersville, MD) on collagen-coated plates or dishes as previously described (28). BOEC can be passaged in vitro for over 30 passages while maintaining their phenotypes. We used cells at passage 7 to 8 for the experiments.

NF- $\kappa B$ super suppressor I $\kappa \mathrm{Ba}$ mutant (I $\kappa \mathrm{BaM}$ ) lentiviral construct (p156RRLsinPPTCMV$\mathrm{I} \kappa \mathrm{BaM}$ ) was provided by Dr. Inder Verma at Salk Institute. vFLIP lentiviral construct was obtained from Dr. Chris Boshoff at UCL Cancer Institute. EZH2 promoter firefly luciferasereporter construct, which contains a DNA fragment from-1,093-bp to +48-bp of the transcriptional start site, was provided by Dr. Felix Hoppe-Seyler at German Cancer Research Center. The thymidine kinase promoter-Renilla luciferase reporter plasmid (pRLTK) was used as a control for transfection efficiency (Promega, Madison, WI). Lentivirus clone TRCN000040076 for one of the EZH2 shRNA constructs was obtained from Open Biosystems (Rockford, IL). A second lentiviral EZH2 shRNA construct was previously described (26). Lentivirus production and infection were performed as previously described (29). Ephrin-B2 shRNA lentiviral particles containing 3 different target-specific constructs were from Santa Cruz Biotechnology (Santa Cruz, CA, sc-39438-V).

\section{KSHV virus production and cell infection}

Recombinant KSHV-GFP was isolated as previously described (27). Isolated virus was purified by centrifugation at 24,000 rpm for $2 \mathrm{~h}$ with a 20/35\% Nycodenz gradient (Thermo Fisher Scientific, Waltham, MA). The gradient junction band containing KSHV was collected. The purified virus preparation was aliquoted and stored at $-80^{\circ} \mathrm{C}$ until use. The purified KSHV was diluted in Opti-MEM I Reduced Serum Medium before use. For KSHV infection, BOEC were plated on collagen-coated 12 -well plate at $3 \times 10^{4}$ cells/well overnight, and mock infected or infected with KSHV at $>80 \%$ infection rates bassed on the percentages 
GFP-positve cells at 2 days post-infection. The concentration of infectious viral particles was determined prior to infection as published (3). To enhance infection efficiency, plates were centrifuged at $3,000 \mathrm{rpm}$ for $1 \mathrm{~h}$ at $25^{\circ} \mathrm{C}$ immediately after addition of KSHV to cells. At $3 \mathrm{~h}$ post-infection, cells were washed $\times 3$ with PBS and cultured in full EGM- 2 medium.

\section{Immunofluorescence and immunohistochemistry}

Immunofluorescence was done as previously described (29). An anti-LANA rat monoclonal antibody (Advanced Biotechnologies Inc, Columbia MD) and a Rhodamine Red ${ }^{\mathrm{TM}}-\mathrm{X}$ conjugated Affinipure Donkey Anti-Rat secondary antibody (Jackson ImmunoResearch Laboratories, Inc, West Grove, PA) were used for LANA staining. Immunohistochemistry for EZH2 was performed on a formalin-fixed paraffin-embedded tissue microarray obtained from the AIDS and Cancer Specimen Resource (ACSR) of the National Cancer Institute. The tissue microarray slide was subjected to citrate antigen retrieval for $30 \mathrm{~min}$ and blocked for nonspecific protein binding with Universal Protein Block (DAKO, Denmark). Slides were incubated with an anti-EZH2 antibody (\#36-6300) (Invitrogen, Carlsbad, CA) at 1:200 followed by an anti-rabbit IgG secondary antibody and a DAB chromogen for color development (Envision, DAKO). LANA staining and hematoxylin and eosin (H\&E) staining of tissue microarray sections from the same block were performed by ACSR. Images were captured using a Nikon E800M microscope equipped with a Nikon DXM1200 digital camera and the Nikon ACT-1 imaging software system (Nikon Instruments Inc., Melville, NY).

\section{Western-blotting}

Western-blotting was performed as previously described (29) using antibodies to EZH2 (Cell Signaling Technology, Danvers, MA), Ephrin-B2 (Abcam, Cambridge, MA) and IкBa (Santa Cruz Biotechnology). GAPDH detected by an antibody (Santa Cruz Biotechnology) was used as a loading control. Immunoreactive bands were visualized by autoradiography following development with an enhanced chemiluminescence system (Amersham, Little Chalfont, UK).

\section{RNA extraction, reverse transcription, and real-time quantitative PCR (qPCR)}

Total RNA was isolated using the Trizol kit (Invitrogen) and treated with DNase I (Ambion, Austin, TX) following the manufacturer's instructions. RNA was reverse-transcribed into cDNA using Superscript II reverse transcriptase as described in the protocol (Invitrogen). Amplification reactions were performed in a $25 \mu \mathrm{l}$ reaction volume containing $50 \mathrm{ng}$ total RNA, specific primers of EZH2, GAPDH, Ephrin-B2 or vFLIP, and SYBR ${ }^{\circledR}$ Advantage ${ }^{\circledR}$ qPCR Premix (Clontech, Mountain View, CA). The specificity of the amplified products was controlled by post-amplification dissociation curve analyses, and agarose gel electrophoresis of the amplified products. The primer sequences are as follows: EZH2-F: 5'TTGTTGGCGGAAGCGTGTAAAATC-3', EZH2-R: 5'TCCCTAGTCCCGCGCAATGAGC-3'; Ephrin-B2-F: 5'GGAAGAAGTTCGACAACAAGTCC-3', Ephrin-B2-R: 5'TTCAGCAAGAGGACCACCAGCGT-3'; GAPDH-F: 5'CGGAGTCAACGGATTTGGTCGTAT-3', GAPDH-R: 5'AGCCTTCTCCATGGTGGTGAAGAC; vFLIP-F: 5'- 
CGTCTACGTGGAGAACAGTGAGCT-3', vFLIP-R: 5'-

CTGGGCACGGATGACAGGGAAGTG-3'. Results were presented as mean $\pm \mathrm{SD}$ from three independent experiments.

\section{Tubule formation assay}

Chilled growth factor-reduced Matrigel (BD Biosciences, Rockville, MA) was added to the wells of pre-chilled 96 -well plate at $70 \mu \mathrm{l} /$ well. The plate was placed in a $37^{\circ} \mathrm{C}$ incubator for 30 min to allow the Matrigel to solidify. BOEC cells were serum-starved overnight, washed with PBS twice, detached with Accutase (Invitrogen), resuspended in full culture medium, and plated at 3,000 cells/well in the 96-well plates containing the solidified Matrigel. Cells were cultured in $\mathrm{CO} 2$ incubator at $37^{\circ} \mathrm{C}$ for $7 \mathrm{~h}$, and images were taken with the Zeiss Axiovert microscope with a 10× objective (Carl Zeiss Microimaging Inc., Thornwood, NY). Tubule length was counted using the Axiovision software (Carl Zeiss Microimaging Inc.). Similar procedures were carried out with the SLK cells except that the step of serum starvation was omitted, and cells were plated at 10,000 cells/well in the Matrigel-coated plate.

\section{Chromatin immunoprecipitation assay (ChIP)}

ChIP assay was performed to detect EZH2 binding to the Ephrin-B2 promoter locus as previously described using antibody to $\mathrm{EZH} 2$ and $\mathrm{IgG}$ as a control (26). The enrichment of EZH2 on Ephrin-B2 promoter locus was calculated as the fold increase of the immunoprecipitated DNA compared to IgG precipitated DNA. Loci of LANA and RTA promoters were used as low and high binding controls as previously described (26). Each data points in ChIP figures were averages of at least three independent ChIPs using three independent chromatin preparations. The primers for LANA promoter locus are: 5'GTTTATAAGTCAGCCGGACCAA-3' (LANA-F) and 5' GATATAACTCCGCCCTCCACTA-3' (LANA-R), which amplify a DNA fragment at 0.5$\mathrm{kb}$ upstream of transcriptional start site. The primers for RTA promoter locus are: 5'CCCCAACACAAGGACCTTTA-3' (RTA-F) and 5'-GCTTTTGGATACCCTGGTGA-3' (RTA-R), which amplify a DNA fragment at 1.0-kb upstream of transcriptional start site. The primers for Ephrin-B2 promoter locus are 5'-TCGCCATGGCTGTGAGAAGGGA-3' (Ephrin-B2-F) and 5'-GGATCGCGGACGCCACTTACT-3' (Ephrin-B2-R), which amplify a DNA fragment from -5-bp to +142-bp of the transcriptional start site.

\section{Report assay}

SLKp cells were co-transfected with both EZH2 promoter firefly luciferase-reporter construct and pRL-TK Renilla luciferase reporter construct using Lipofectamine 2000 (Invitrogen). Cells were split at $24 \mathrm{~h}$ post-transfection at $4 \times 10^{4}$ cells/well on 12 -well plate. Cells were treated with Bay-11 at $38 \mathrm{~h}$ post-transfection for $10 \mathrm{~h}$. Dual luciferase assay was then performed following the instructions of the manufacturer (Promega). 


\section{Results}

\section{EZH2 is overexpressed in KSHV tumors}

EZH2 deregulation is observed in various malignancies and associated with tumor cell proliferation and angiogenesis $(18,19,22)$. We examined the expression of EZH2 in KS tumors in a tissue microarray consisting of 38 normal biopsies and $173 \mathrm{KS}$ biopsies from different organs. EZH2 was highly expressed in KS specimens compared to normal controls (Table 1). Of 38 normal specimens, only 4 (11\%) had weak EZH2 staining. In contrast, among the $173 \mathrm{KS}$ specimens, 157 (91\%) had strong EZH2 staining. Fig. 1 showed the representative staining EZH2 patterns in skin and lymph node KS specimens. Of 25 lymph node KS, 24 (96\%) had strong EZH2 staining (Table 1). In contrast, only 1 of the 28 (4\%) normal control lymph node specimens had weak EZH2 staining. Of 77 skin KS, 75 (97\%) were positive for EZH2 while only 1 of 5 (20\%) normal skin controls showed very light EZH2 staining (Table 1). The weak staining of this normal skin sample was due to nonspecific uptake by the macrophages. Insufficient clinical data on the KS specimens was available for further analysis of the correlation of the EZH2 staining pattern and intensity with KS disease status.

\section{KSHV infection up-regulates EZH2 in endothelial cells}

To determine whether KSHV infection induced EZH2 expression in endothelial cells in culture, we infected BOEC cells with KSHV. BOEC cells are derived from blood circulating precursor cells and have typical endothelial cobblestone morphology and features (28). BOEC cells harbor KSHV in KS patients and support KSHV infection (30). Almost all cells in the KSHV-infected BOEC cultures were LANA-positive 5 days after infection (Fig. 2A) without detectable expression of viral lytic protein ORF65 (data not shown), indicating that these cells were latently infected by KSHV. As expected, KSHV infection converted the BOEC cells from cobblestone shape to spindle shape (Supplementary Fig. S1A) with an increase in the expression of lymphatic markers FLT1, PROX1, LYVE1, and podoplanin (Supplementary Fig. S1B). Thus, similar to vascular endothelial cells (4-6), KSHV infection reprograms BOEC cells to acquire markers of lymphatic endothelial cells, which are features of KS tumor cells. As shown in Fig. 2B, KSHV infection of BOEC cells increased the expression of EZH2 mRNA and protein. Histone $\mathrm{H} 3$ is a known substrate of the PRC2. One of the common marks targeted by PRC2 is $\mathrm{H} 3 \mathrm{~K} 27 \mathrm{me} 3$. Consistent with the upregulation of EZH2, KSHV infection also increased the level of H3K27me3 in BOEC cells (Fig. 2B). To further confirm these observations, we examined the EZH2 expression in SLK cells with and without KSHV infection. SLK cells are KSHV-negative endothelial cells isolated from a KS tumor. Similar to BOEC, KSHV established latent infection in SLK cells based on the detection of LANA protein (Fig. 2C) but not lytic protein ORF65 (data not shown). Compared to uninfected cells (SLKn), KSHV infection of SLK cells (SLKp) led to the upregulation of EZH2 protein, and an increase in H3K27me3 (Fig. 2D). Together these data indicate that KSHV infection up-regulated EZH2, and caused an increase of its substrate H3K27me3 in endothelial cells. 


\section{KSHV up-regulation of EZH2 is mediated by the NF- $x B$ pathway and viral latent genes vFLIP and LANA}

Activation of NF- $\mathrm{kB}$ pathway has been shown to up-regulate the expression of EZH2 (31).

Since the NF- $\kappa B$ pathway is constitutively activated in KSHV-infected cells (32), we determined whether it might mediate KSHV induction of EZH2 expression. Indeed, inhibition of the NF- $\mathrm{kB}$ pathway with specific inhibitor Bay-11 reduced the expression of EZH2 protein in a dose-dependent manner in SLKp cells (Fig. 3A). Similar results were also observed in BOEC cells. To confirm these results, we inhibited the NF- $\kappa B$ pathway with a super suppressor I $\mathrm{KBaM}$. Expression of I $\mathrm{KBaM}$ reduced the expression of EZH2 protein (Fig. 3A). Bay-11 also inhibited the expression of EZH2 mRNA by $80 \%$ (Fig 3B); however, it only inhibited EZH2 promoter activity by $40 \%$ in a reporter assay, suggesting that the NF$\mathrm{\kappa B}$ pathway might only partially regulate the expression of EZH2 at the transcriptional level. Alternative mechanism such as mRNA stability might also be involved in the regulation of EZH2 mRNA level by this pathway.

Because KSHV established latent infection in both BOEC and SLK cells, we searched for latent genes that might activate the NF- $\mathrm{kB}$ pathway and cause the upregulation of EZH2. We focused on vFLIP and LANA because both of them have been shown to activate the NF$\kappa B$ pathway $(33,34)$. Indeed, expression of vFLIP in BOEC cells up-regulated the expression of EZH2 at both protein and mRNA levels, which was inhibited by Bay-11 (Fig. 3C). Since we were not able to obtain a functional antibody to vFLIP, we examined the expression of vFLIP mRNA by reverse transcription qPCR (RT-qPCR). We detected robust expression of vFLIP mRNA in the vFLIP-transduced cells, which was not affected by Bay-11 (Fig. 3C). Similar to vFLIP, expression of LANA also increased the expression of EZH2, however, to a less extent, by less than 2-fold, in BOEC cells (Fig 3C). In contrast to vFLIP and LANA, we did not observe any increase in EZH2 expression following the expression of KSHV latent gene vCyclin (ORF72, data not shown). KSHV infection induces inflammatory cytokines, some of which can activate the NF- $\kappa B$ pathway. Conditioned medium from KSHV-infected BOEC cells only marginally increased the expression of EZH2 protein (Fig 3D). Together, these results indicated that KSHV upregulation of EZH2 is mainly mediated by vFLIP and LANA through the NF- $\kappa$ B pathway in latent KSHVinfected endothelial cells.

\section{Induction of EZH2 is essential for KSHV-induced angiogenesis}

Overexpression of EZH2 is often associated with advanced stage of tumors $(19,35)$. EZH2 has been shown to regulate cancer angiogenesis $(22,24)$. We determined whether KSHVinduced up-regulation of EZH2 contributed to KSHV-induced angiogenesis. We used an in vitro Matrigel tubulogenesis assay to measure the angiogenic activity of endothelial cells. KSHV infection of BOEC cells increased the expression of EZH2 as well as tubule formation while knockdown of EZH2 reduced tubule formation (Fig. 4A). Similar results were also observed in SLK cells (Fig. 4B). These results indicate that EZH2 mediated KSHV-induced angiogenesis. 


\section{EZH2 regulation of KSHV-induced angiogenesis is mediated by Ephrin-B2}

To delineate the mechanism involved in EZH2-mediated KSHV-induced tubule formation, we screened a panel of pro-angiogenic genes that could be regulated by EZH2 in KSHVinfected endothelial cells. We found that Ephrin ligand Ephrin-B2 protein was up-regulated in KSHV-infected BOEC cells and constitutively expressed in SLKp cells (Fig. 5A). Knockdown of EZH2 reduced the expression of Ephrin-B2 protein (Fig. 5A). Upregulation of Ephrin-B2 by KSHV was also observed at the mRNA level (Fig. 5B). Knockdown of EZH2 reduced the expression of Ephrin-B2 mRNA in KSHV-infected BOEC cells (Fig. 5B). To further determine if EZH2 directly binds to the Ephrin-B2 promoter to regulate its expression, we carried out ChIP assay in KSHV-infected SLKp cells. A previous study has shown that EZH2 binds strongly to the RTA promoter chromatin but weakly to the LANA promoter chromatin in KSHV-infected cells. We used these KSHV loci as controls for our experiments. Indeed, compared to IgG control, an EZH2 specific antibody enriched 18 -fold of the RTA promoter chromatin but only 3.1-fold of the LANA promoter chromatin (Fig. 5C). Knockdown of EZH2 reduced its binding to the RTA promoter chromatin by $82 \%$ but had marginal effect on the LANA promoter chromatin (Fig. 5C). Similar to the RTA promoter, EZH2 enriched Ephrin-B2 promoter chromatin by 13-fold (Fig. 5C). Knockdown of EZH2 reduced its binding to the Ephrin-B2 promoter chromatin by $70 \%$ (Fig. 5C). These results indicated that EZH2 regulates the expression of Ephrin-B2 by directly binding to its promoter.

It has been shown that Ephrin-B2 is highly expressed in KS tissues, and KSHV infection upregulated the expression of Ephrin-B2 in human endothelial cells (13). Furthermore, inhibition of the Eph pathway is sufficient to decrease cell growth, migration and angiogenesis of KS cells (36). Indeed, knockdown of either Ephrin-B2 or EZH2 inhibited the proliferation of KSHV-infected BOEC and SLK cells as indicated by the significant lower numbers of cells per field at 3 days post-transduction with the specific shRNAs (Fig. 6A and B). Knockdown of Ephrin-B2 also inhibited tubule formation of KSHV-infected BOEC and SLK cells (Fig. 6A and B).

\section{Discussion}

EZH2 was initially described as a controller of cell differentiation and organism development. It is highly expressed in stem cells (16). Expression of EZH2 is required for the inhibition of differentiated genes and maintenance of the identity of stem cells (37). The expression of EZH2 decreases once stem cells differentiated into specific type of cells (38). Subsequent studies revealed EZH2's roles in normal cell proliferation and cell cycle control as well as progression of cancer. In cell culture, over-expression of EZH2 induces cell invasion, growth in soft agar, and motility; while knockdown of EZH2 inhibits cell proliferation and cell invasion $(18,35)$. Dysregulation of EZH2 has been associated with tumor aggressiveness, therapeutic refractory, and tumor angiogenesis in prostate, breast and ovarian cancer cells $(18,19,22)$. EZH2 is regulated by several pathways including retinoblastoma-E2F (39), c-Myc (40), NF- $\mathrm{B}$ (31), and p53 (41) pathways, as well as several microRNAs $(23,40)$. In this study, we have found that EZH2 is highly expressed in KS tumors, and highly up-regulated in KSHV-infected endothelial cells. Furthermore, we 
have shown that KSHV-induced up-regulation of EZH2 is mediated by the NF- $\mathrm{KB}$ pathway and KSHV latent genes vFLIP and LANA.

Like all herpesvirus, KSHV has both latent and lytic phases in its life cycle. Most tumor cells in KS lesions display KSHV latent replication program, expressing only a handful of latent gene products that are involved in host cell survival, proliferation and manipulation of the tumor microenvironment. Among KSHV latent genes, vFLIP and LANA have been shown to activate the NF- $\mathrm{BB}$ pathway $(33,34)$. Our results have shown that KSHV upregulation of EZH2 is mainly mediated by vFLIP, and to a less extent, by LANA. Our previous study has shown that vFLIP inhibits KSHV lytic replication program to promote viral latency through activation of the NF- $\kappa$ B pathway and inhibition of the AP-1 pathway (42). A recent study has shown that EZH2 mediates KSHV latency in primary effusion lymphomas and in KSHV-infected endothelial cells by regulating latency-specific histone repressive modifications such as $\mathrm{H} 3 \mathrm{~K} 27 \mathrm{me} 3$ (26). Thus, in addition to the AP-1 pathway, this study has identified EZH2 as a new cellular target that mediates vFLIP regulation of KSHV latency through the NF- $\kappa B$ pathway.

Because KS is a highly angiogenic tumor, and KSHV infection of endothelial cells enhances the angiogenic phenotype of these cells, we examined the effect of up-regulation of EZH2 on KSHV-induced tubule formation on Matrigel. EZH2 is an epigenetic repressor and inhibited the expression of several tumor suppressor genes, including p16, E-cadherin, DAB2IP and RUNX3 among others (35). Up-regulation of EZH2 by VEGF promotes angiogenesis by inhibiting the expression of angiogenesis inhibitor VASH1 through epigenetic silencing (22). Maspin, an angiogenesis inhibitor, is also down-regulated by EZH2 in a microarray analysis (38). Examination of KSHV-infected BOEC cells showed that the expression of both genes were at the lower detection limit of RT-qPCR albeit VASH1 appeared to be down-regulated. Interestingly, we did not observe any significant increases in the expression of VASH1 following EZH2 knock down (data not shown). In addition to angiogenesis inhibitors, we have also examined pro-angiogenenic factors including Eph ligand Ephrin-B2, Notch ligands Jag1 and DLL4, VEGFR3, MMP-2 and MMP-9. Among these factors, Ephrin-B2 is the only one consistently up-regulated following KSHV infection. Knockdown of EZH2 down-regulated the expression of EphrinB2 in KSHV-infected BOEC and SLK cells.

Ephrin-B2 is a transmembrane ligand, and regulates angiogenic growth of the blood vessel and lymphatic endothelium (43). Eph-ephrin binding leads to bidirectional signaling in cells expressing the receptor (forward signaling) or ligand (reverse signaling). Ephrin-B2 is upregulated during physiological and pathological angiogenesis in the adult, and loss of Ephrin-B2 leads to vascular defects (44). Intriguingly, Ephrin-B2-mediated reverse signaling controls VEGFR internalization. Endothelial cells lacking Ephrin-B2 reverse signaling are unable to internalize VEGFR2 and VEGFR3, and cannot properly transmit VEGF signals, resulting in impairment of angiogenesis $(45,46)$. Previous studies have shown that EphrinB2 is highly expressed in KS tissues; KSHV infection up-regulates Ephrin-B2 in endothelial cells (13); and the inhibition of Ephrin-B2 blocked tumor growth, and reduced tumor vessel density and perfusion in a KS tumor xenograft model (36). Our results have confirmed that Ephrin-B2 expression is increased following KSHV infection. Furthermore, we have shown 
that knockdown of EZH2 inhibits Ephrin-B2 expression at both protein and mRNA levels, and knockdown either Ephrin-B2 or EZH2 inhibits cell growth and tubule formation in KSHV-infected endothelial cells.

EZH2 and its associated PRC2 complex typically repress or maintain the repression status of their target genes $(37,47,48)$. EZH2 is associated with the promoters of a number of tumor suppressor genes and therefore inhibits their expression $(35,47)$. However, EZH2 also upregulates some positive regulators, including CCND1, CCNE1, CCNA2 and c-Myb among others $(20,39)$. A recent study has shown that $\mathrm{EZH} 2$, through interacting with RelA/RelB, is required for the establishment of constitutive activation of a subset of NF- $\kappa$ B targeted genes (49). Our results have demonstrated that $\mathrm{EZH} 2$ binds to the promoter of angiogenesis enhancer Ephrin-B2 and up-regulated its expression, indicating EZH2 might also be required for either the activation or the maintenance of the activated state of this positive angiogenesis regulator. Further studies are required to delineate the mechanism mediating this positive regulation.

In summary, we have shown that KSHV promotes angiogenesis by up-regulating a proangiogenic Ephrin-B2 through EZH2. These findings suggest that both EZH2 and Ephrin$\mathrm{B} 2$ are promising novel targets for $\mathrm{KSHV}$-induced angiogenesis.

\section{Supplementary Material}

Refer to Web version on PubMed Central for supplementary material.

\section{Acknowledgments}

We would like to thank Drs. Adam Grundhoff, Robert Hebbel, Inder Verma, Chris Boshoff, and Felix HoppeSeyler for providing us critical reagents, Paula Overn in the Comparative Pathology Shared Resource, Masonic Cancer Center at the University of Minnesota for her technical assistance for the IHC experiments, and members of Dr. Gao's laboratory for technical assistance and helpful discussions.

\section{Grant support:}

This work was funded by an American Cancer Society Research Scholar Grant (RSG-10-060-01-MPC) to M.C, and NIH grants to SJG (R01CA132637, R01CA124332 and R01CA096512).

\section{References}

1. Mesri EA, Cesarman E, Boshoff C. Kaposi's sarcoma and its associated herpesvirus. Nature reviews. Cancer. 2010; 10:707-719.

2. Ciufo DM, Cannon JS, Poole LJ, Wu FY, Murray P, Ambinder RF, et al. Spindle cell conversion by Kaposi's sarcoma-associated herpesvirus: formation of colonies and plaques with mixed lytic and latent gene expression in infected primary dermal microvascular endothelial cell cultures. J Virol. 2001; 75:5614-5626. [PubMed: 11356969]

3. Gao SJ, Deng JH, Zhou FC. Productive lytic replication of a recombinant Kaposi's sarcomaassociated herpesvirus in efficient primary infection of primary human endothelial cells. J Virol. 2003; 77:9738-9749. [PubMed: 12941882]

4. Hong YK, Foreman K, Shin JW, Hirakawa S, Curry CL, Sage DR, et al. Lymphatic reprogramming of blood vascular endothelium by Kaposi's sarcoma-associated herpesvirus. Nat Genet. 2004; 36:683-685. [PubMed: 15220917] 
5. Wang HW, Trotter MW, Lagos D, Bourboulia D, Henderson S, Makinen T, et al. Kaposi's sarcoma herpesvirus-induced cellular reprogramming contributes to the lymphatic endothelial gene expression in Kaposi sarcoma. Nat Genet. 2004; 36:687-693. [PubMed: 15220918]

6. Carroll PA, Brazeau E, Lagunoff M. Kaposi's sarcoma-associated herpesvirus infection of blood endothelial cells induces lymphatic differentiation. Virology. 2004; 328:7-18. [PubMed: 15380353]

7. Ye FC, Blackbourn DJ, Mengel M, Xie JP, Qian LW, Greene W, et al. Kaposi's sarcoma-associated herpesvirus promotes angiogenesis by inducing angiopoietin-2 expression via AP-1 and Ets1. J Virol. 2007; 81:3980-391. [PubMed: 17287278]

8. Qian LW, Xie J, Ye F, Gao SJ. Kaposi's sarcoma-associated herpesvirus infection promotes invasion of primary human umbilical vein endothelial cells by inducing matrix metalloproteinases. $\mathrm{J}$ Virol. 2007; 81:7001-7010. [PubMed: 17442715]

9. Qian LW, Greene W, Ye F, Gao SJ. Kaposi's sarcoma-associated herpesvirus disrupts adherens junctions and increases endothelial permeability by inducing degradation of VE-cadherin. J Virol. 2008; 82:11902-11912. [PubMed: 18815301]

10. Shin YC, Joo CH, Gack MU, Lee HR, Jung JU. Kaposi's sarcoma-associated herpesvirus viral IFN regulatory factor 3 stabilizes hypoxia-inducible factor-1 alpha to induce vascular endothelial growth factor expression. Cancer Res. 2008; 68:1751-1759. [PubMed: 18339855]

11. Wang L, Damania B. Kaposi's sarcoma-associated herpesvirus confers a survival advantage to endothelial cells. Cancer Res. 2008; 68:4640-4648. [PubMed: 18559509]

12. Xie J, Pan H, Yoo S, Gao SJ. Kaposi's sarcoma-associated herpesvirus induction of AP-1 and interleukin 6 during primary infection mediated by multiple mitogen-activated protein kinase pathways. J Virol. 2005; 79:15027-15037. [PubMed: 16306573]

13. Masood R, Xia G, Smith DL, Scalia P, Still JG, Tulpule A, et al. Ephrin B2 expression in Kaposi's sarcoma is induced by human herpesvirus type 8: phenotype switch from venous to arterial endothelium. Blood. 2005; 105:1310-1318. [PubMed: 15471957]

14. Sivakumar R, Sharma-Walia N, Raghu H, Veettil MV, Sadagopan S, Bottero V, et al. Kaposi's sarcoma-associated herpesvirus induces sustained levels of vascular endothelial growth factors A and $\mathrm{C}$ early during in vitro infection of human microvascular dermal endothelial cells: biological implications. J Virol. 2008; 82:1759-1776. [PubMed: 18057235]

15. Iso T, Maeno T, Oike Y, Yamazaki M, Doi H, Arai M, et al. Dll4-selective Notch signaling induces ephrinB2 gene expression in endothelial cells. Biochem Biophys Res Commun. 2006; 341:708-714. [PubMed: 16430858]

16. Sauvageau M, Sauvageau G. Polycomb group proteins: multi-faceted regulators of somatic stem cells and cancer. Cell Stem Cell. 2010; 7:299-313. [PubMed: 20804967]

17. Vire E, Brenner C, Deplus R, Blanchon L, Fraga M, Didelot C, et al. The Polycomb group protein EZH2 directly controls DNA methylation. Nature. 2006; 439:871-874. [PubMed: 16357870]

18. Chang CJ, Yang JY, Xia W, Chen CT, Xie X, Chao CH, et al. EZH2 promotes expansion of breast tumor initiating cells through activation of RAF1-beta-catenin signaling. Cancer Cell. 2011; 19:86-100. [PubMed: 21215703]

19. Varambally S, Dhanasekaran SM, Zhou M, Barrette TR, Kumar-Sinha C, Sanda MG, et al. The polycomb group protein EZH2 is involved in progression of prostate cancer. Nature. 2002; 419:624-629. [PubMed: 12374981]

20. Shi B, Liang J, Yang X, Wang Y, Zhao Y, Wu H, et al. Integration of estrogen and Wnt signaling circuits by the polycomb group protein EZH2 in breast cancer cells. Mol Cell Biol. 2007; 27:5105-5119. [PubMed: 17502350]

21. McCabe MT, Graves AP, Ganji G, Diaz E, Halsey WS, Jiang Y, et al. Mutation of A677 in histone methyltransferase EZH2 in human B-cell lymphoma promotes hypertrimethylation of histone H3 on lysine 27 (H3K27). Proc Natl Acad Sci USA. 2012; 109:2989-2994. [PubMed: 22323599]

22. Lu C, Han HD, Mangala LS, Ali-Fehmi R, Newton CS, Ozbun L, et al. Regulation of tumor angiogenesis by EZH2. Cancer Cell. 2010; 18:185-197. [PubMed: 20708159]

23. Kottakis F, Polytarchou C, Foltopoulou P, Sanidas I, Kampranis SC, Tsichlis PN. FGF-2 regulates cell proliferation, migration, and angiogenesis through an NDY1/KDM2B-miR-101-EZH2 pathway. Mol Cell. 2011; 43:285-298. [PubMed: 21777817] 
24. Smits M, Nilsson J, Mir SE, van der Stoop PM, Hulleman E, Niers JM, et al. miR-101 is downregulated in glioblastoma resulting in EZH2-induced proliferation, migration, and angiogenesis. Oncotarget. 2010; 1:710-720. [PubMed: 21321380]

25. Gunther T, Grundhoff A. The epigenetic landscape of latent Kaposi's sarcoma-associated herpesvirus genomes. PLoS Pathog. 2010; 6:e1000935. [PubMed: 20532208]

26. Toth Z, Maglinte DT, Lee SH, Lee HR, Wong LY, Brulois KF, et al. Epigenetic analysis of KSHV latent and lytic genomes. PLoS Pathog. 2010; 6:e1001013. [PubMed: 20661424]

27. Grundhoff A, Ganem D. Inefficient establishment of KSHV latency suggests an additional role for continued lytic replication in Kaposi's sarcoma pathogenesis. J Clin Invest. 2004; 113:124-136. [PubMed: 14702116]

28. Lin Y, Weisdorf DJ, Solovey A, Hebbel RP. Origins of circulating endothelial cells and endothelial outgrowth from blood. J Clin Invest. 2000; 105:71-77. [PubMed: 10619863]

29. He M, Bakken T, Kassimova A, Boshoff C, Philpott N, Cannon ML. Focal adhesion kinase is required for KSHV vGPCR signaling. Mol Carcinog. 2011

30. Della Bella S, Taddeo A, Calabro ML, Brambilla L, Bellinvia M, Bergamo E, et al. Peripheral blood endothelial progenitors as potential reservoirs of Kaposi's sarcoma-associated herpesvirus. PLoS One. 2008; 3:e1520. [PubMed: 18231605]

31. Trenkmann M, Brock M, Gay RE, Kolling C, Speich R, Michel BA, et al. Expression and function of EZH2 in synovial fibroblasts: epigenetic repression of the Wnt inhibitor SFRP1 in rheumatoid arthritis. Ann Rheum Dis. 2011; 70:1482-1488. [PubMed: 21515604]

32. Keller SA, Hernandez-Hopkins D, Vider J, Ponomarev V, Hyjek E, Schattner EJ, et al. NF-kappaB is essential for the progression of KSHV- and EBV-infected lymphomas in vivo. Blood. 2006; 107:3295-3302. [PubMed: 16380446]

33. Matta H, Chaudhary PM. Activation of alternative NF-kappa B pathway by human herpes virus 8encoded Fas-associated death domain-like IL-1 beta-converting enzyme inhibitory protein (vFLIP). Proc Natl Acad Sci USA. 2004; 101:9399-9404. [PubMed: 15190178]

34. Konrad A, Wies E, Thurau M, Marquardt G, Naschberger E, Hentschel S, et al. A systems biology approach to identify the combination effects of human herpesvirus 8 genes on NF-kappaB activation. J Virol. 2009; 83:2563-2574. [PubMed: 19129458]

35. Chang CJ, Hung MC. The role of EZH2 in tumour progression. Br J Cancer. 2012; 106:243-247. [PubMed: 22187039]

36. Scehnet JS, Ley EJ, Krasnoperov V, Liu R, Manchanda PK, Sjoberg E, et al. The role of Ephs, Ephrins, and growth factors in Kaposi's sarcoma and implications of EphrinB2 blockade. Blood. 2009; 113:254-263. [PubMed: 18836096]

37. Delgado-Olguin P, Huang Y, Li X, Christodoulou D, Seidman CE, Seidman JG, et al. Epigenetic repression of cardiac progenitor gene expression by Ezh2 is required for postnatal cardiac homeostasis. Nat Genet. 2012; 44:343-347. [PubMed: 22267199]

38. Velichutina I, Shaknovich R, Geng H, Johnson NA, Gascoyne RD, Melnick AM, et al. EZH2mediated epigenetic silencing in germinal center B cells contributes to proliferation and lymphomagenesis. Blood. 2010; 116:5247-5255. [PubMed: 20736451]

39. Bracken AP, Pasini D, Capra M, Prosperini E, Colli E, Helin K. EZH2 is downstream of the pRBE2F pathway, essential for proliferation and amplified in cancer. EMBO J. 2003; 22:5323-5335. [PubMed: 14532106]

40. Sander S, Bullinger L, Klapproth K, Fiedler K, Kestler HA, Barth TF, et al. MYC stimulates EZH2 expression by repression of its negative regulator miR-26a. Blood. 2008; 112:4202-4212. [PubMed: 18713946]

41. Tang X, Milyavsky M, Shats I, Erez N, Goldfinger N, Rotter V. Activated p53 suppresses the histone methyltransferase EZH2 gene. Oncogene. 2004; 23:5759-5769. [PubMed: 15208672]

42. Ye FC, Zhou FC, Xie JP, Kang T, Greene W, Kuhne K, et al. Kaposi's sarcoma-associated herpesvirus latent gene vFLIP inhibits viral lytic replication through NF-kappaB-mediated suppression of the AP-1 pathway: a novel mechanism of virus control of latency. J Virol. 2008; 82:4235-4249. [PubMed: 18305042]

43. Kullander K, Klein R. Mechanisms and functions of Eph and ephrin signalling. Nat Rev Mol Cell Biol. 2002; 3:475-486. [PubMed: 12094214] 
44. Salvucci O, Maric D, Economopoulou M, Sakakibara S, Merlin S, Follenzi A, et al. EphrinB reverse signaling contributes to endothelial and mural cell assembly into vascular structures. Blood. 2009; 114:1707-1716. [PubMed: 19411631]

45. Sawamiphak S, Seidel S, Essmann CL, Wilkinson GA, Pitulescu ME, Acker T, et al. Ephrin-B2 regulates VEGFR2 function in developmental and tumour angiogenesis. Nature. 2010; 465:487491. [PubMed: 20445540]

46. Wang Y, Nakayama M, Pitulescu ME, Schmidt TS, Bochenek ML, Sakakibara A, et al. Ephrin-B2 controls VEGF-induced angiogenesis and lymphangiogenesis. Nature. 2010; 465:483-486. [PubMed: 20445537]

47. Cheng AS, Lau SS, Chen Y, Kondo Y, Li MS, Feng H, et al. EZH2-mediated concordant repression of Wnt antagonists promotes beta-catenin-dependent hepatocarcinogenesis. Cancer Res. 2011; 71:4028-4039. [PubMed: 21512140]

48. Paul TA, Bies J, Small D, Wolff L. Signatures of polycomb repression and reduced H3K4 trimethylation are associated with p15INK4b DNA methylation in AML. Blood. 2010; 115:30983108. [PubMed: 20190193]

49. Lee ST, Li Z, Wu Z, Aau M, Guan P, Karuturi RK, et al. Context-specific regulation of NFkappaB target gene expression by EZH2 in breast cancers. Mol Cell. 2011; 43:798-810. [PubMed: 21884980] 


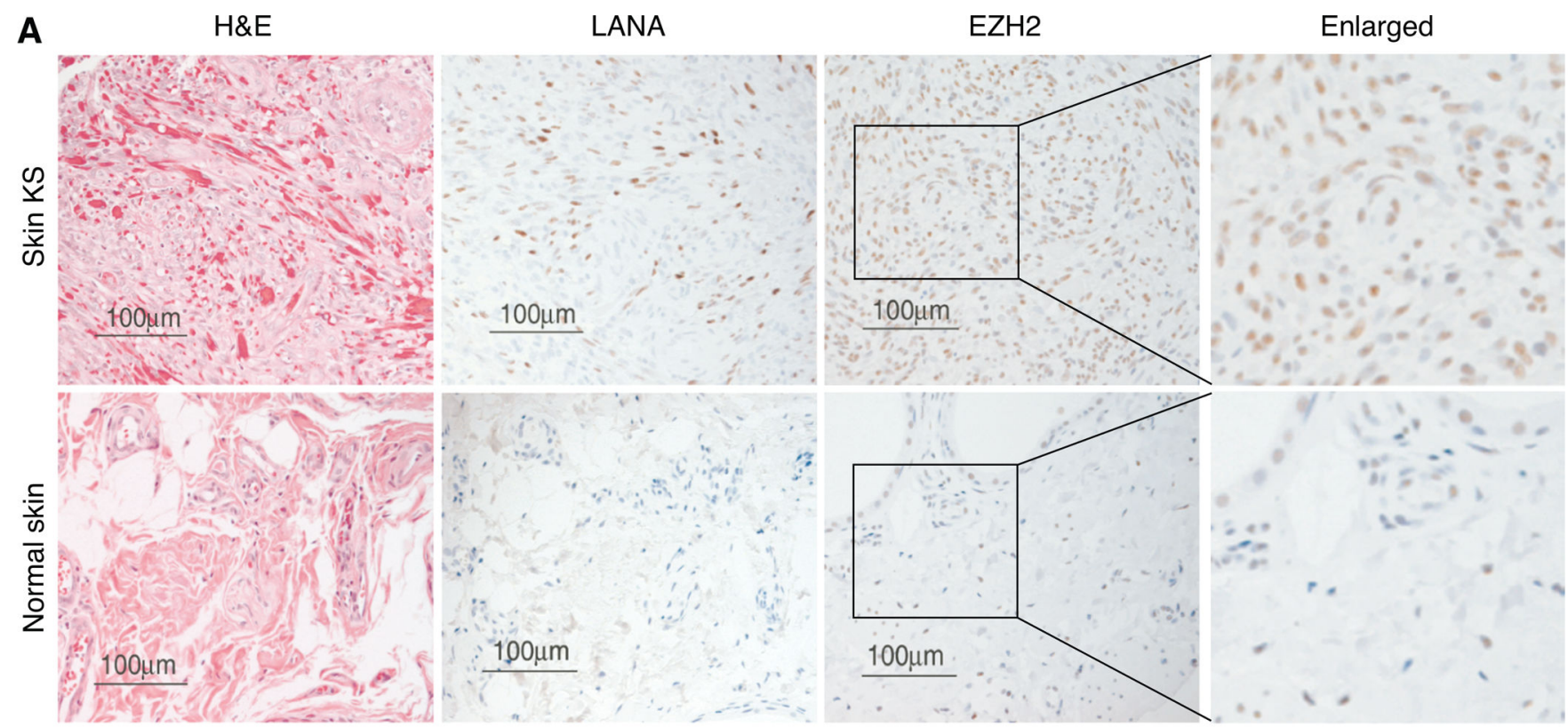

B

$H \& E$ LANA $\mathrm{EZH} 2$

Enlarged
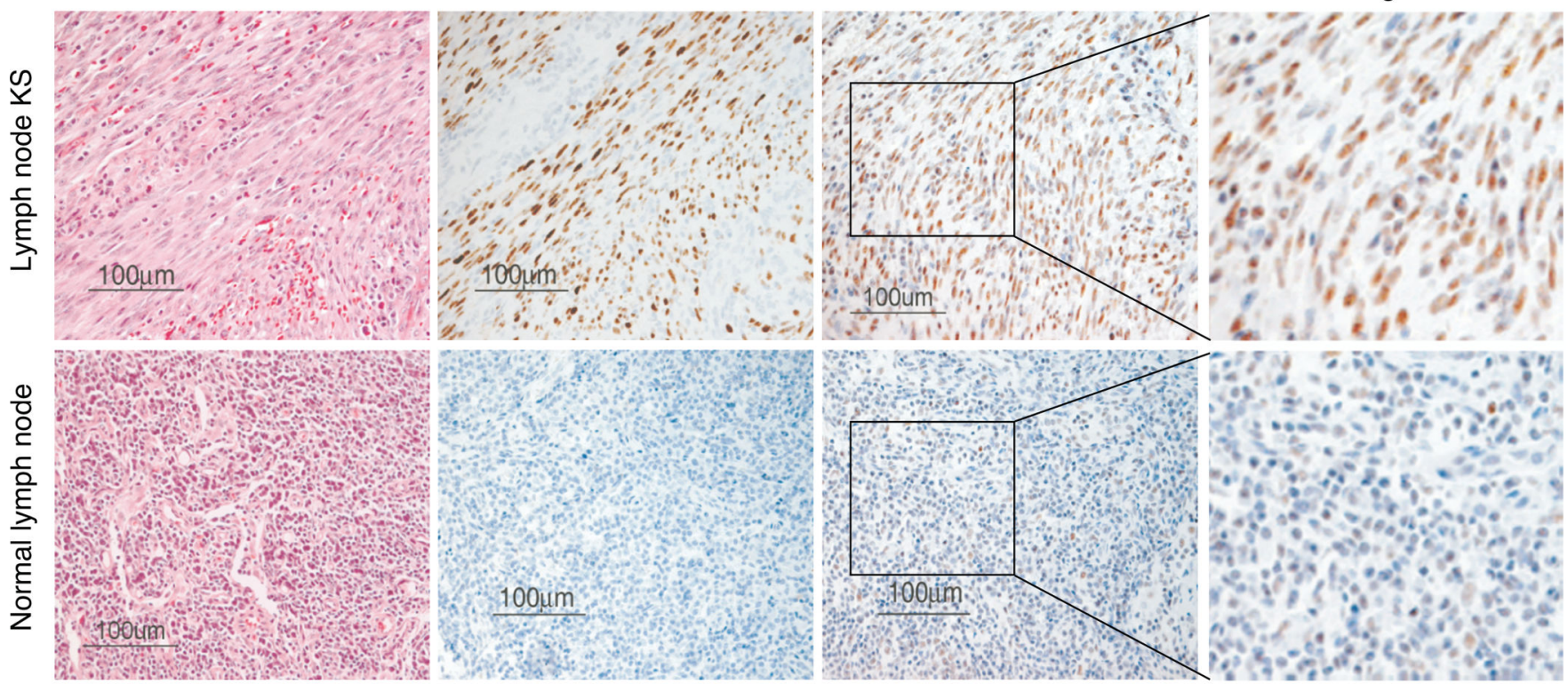

Figure 1.

EZH2 is highly expressed in KS tumors. Immunohistochemical staining of EZH2 protein in a paraffin-embedded tissue microarray consisting of KS and control tissues. A,

Representative images of hematoxylin and eosin (H\&E), LANA and EZH2 staining of a skin KS and a normal skin control. B, Representative images of H\&E, LANA and EZH2 staining of a lymph node KS and a normal lymph node control. 

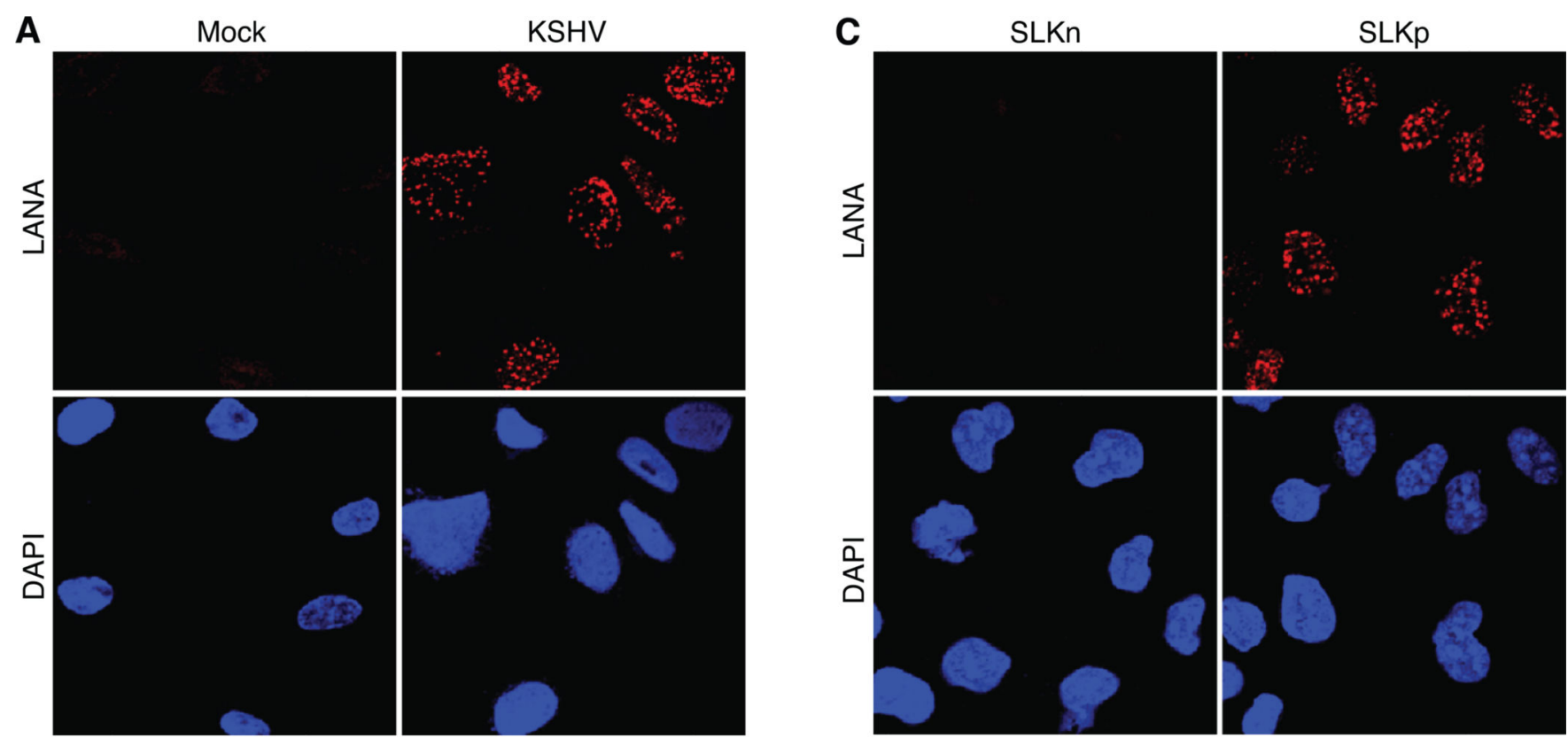

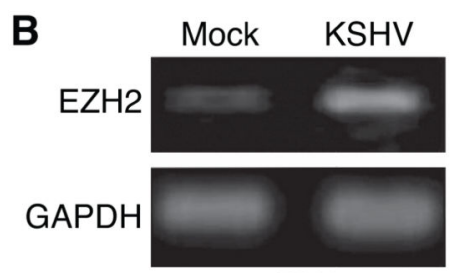

mRNA

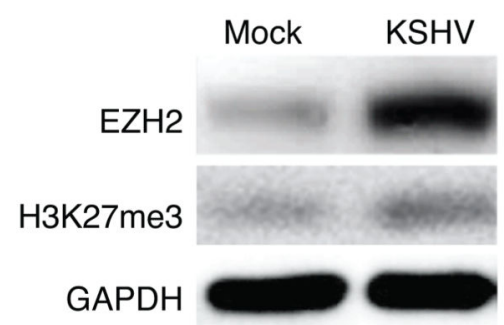

Protein

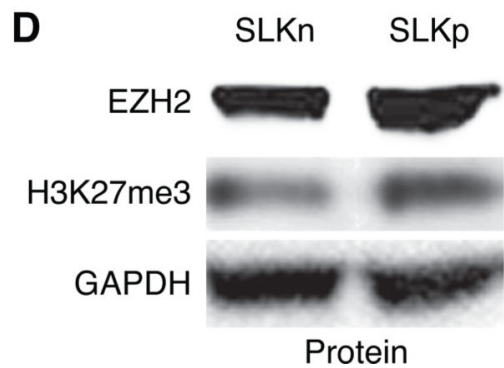

Figure 2.

KSHV infection upregulates EZH2 expression in human endothelial cells. A, LANA staining of mock- and KSHV-infected BOEC cells. Immunofluorescence staining was performed at 5 days post-infection. B, KSHV-infection upregulated the expression of EZH2 mRNA and protein, as well as the level of H3K27me3 in BOEC cells. EZH2 mRNA was detected by semi-quantitative RT-PCR (left panel) and Western-blotting was performed for EZH2 and H3K27me3 (right panel) at 5 days post-infection. C, LANA staining of uninfected SLK cells (SLKn) and KSHV-infected SLK cells (SLKp). D, KSHV-infection upregulated the expression of EZH2 protein and the level of H3K27me3 in SLK cells. 

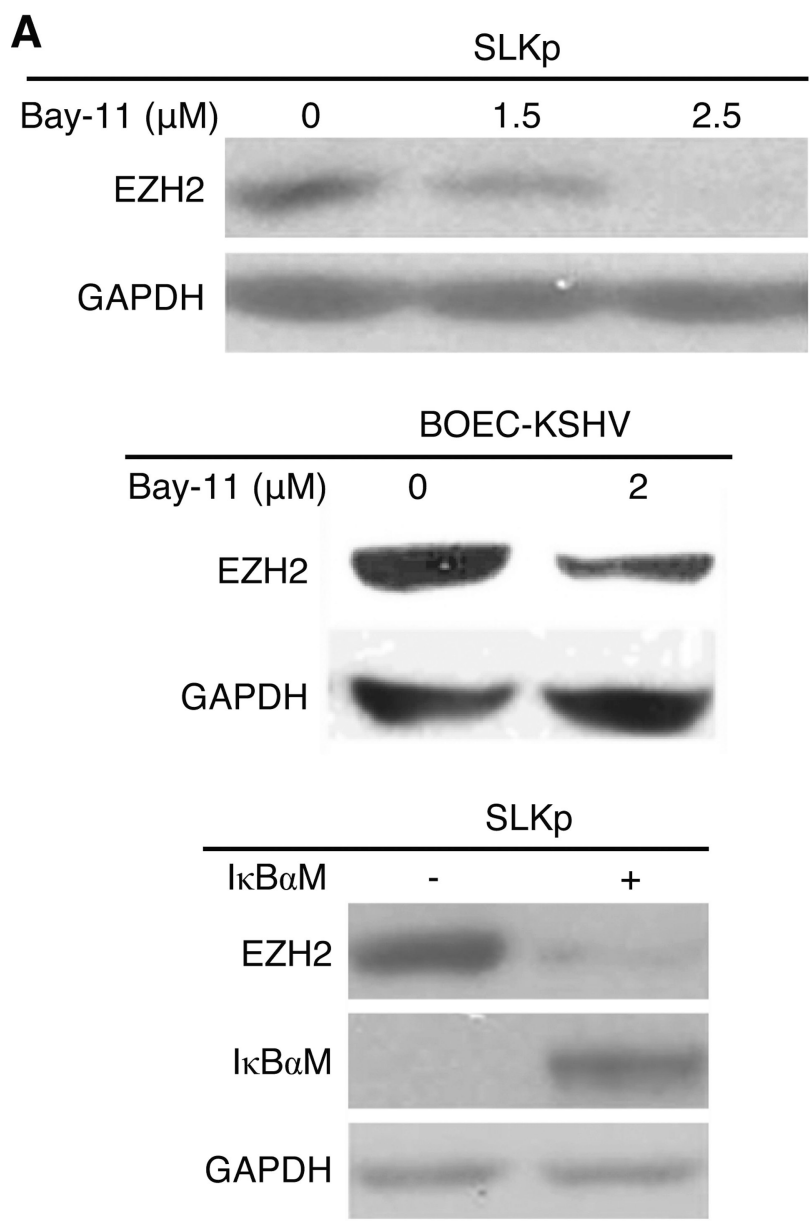

B

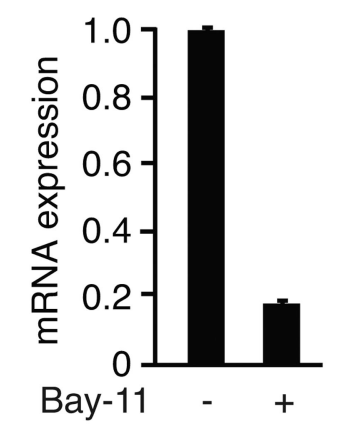

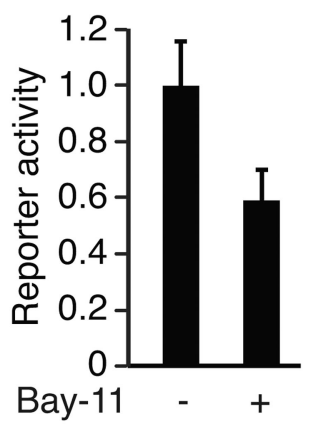
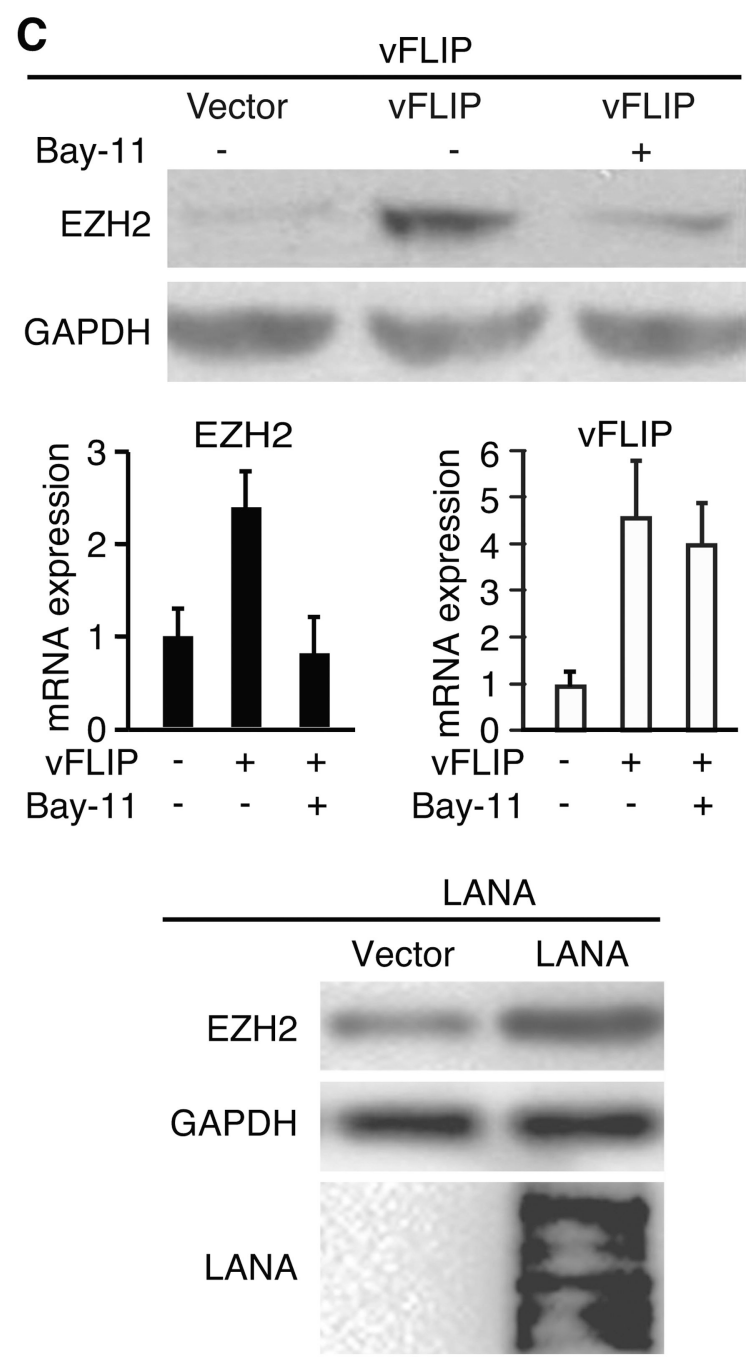

D

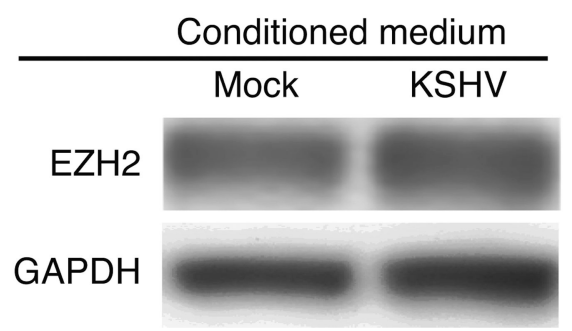

Figure 3.

Up-regulation of EZH2 in KSHV-infected endothelial cells is mediated by the NF- $\kappa \mathrm{B}$ pathway, and by viral latent genes vFLIP and LANA. A, Inhibition of the NF- $\kappa$ B pathway decreases the expression of EZH2 protein. Cells were either treated with Bay-11 at the indicated concentrations for $24 \mathrm{~h}$ (SLKp and BOEC cells at the upper and middle panels, respectively) or transduced with I $\kappa$ BaM for $48 \mathrm{~h}$ (SLKp cells at the lower panel), and examined for the expression of EZH2 protein. B, Inhibition of the NF- $\kappa$ B pathway decreases the mRNA expression and promoter reporter activity of EZH2 in SLKp cells. For mRNA 
detection, cells were treated with $2.5 \mu \mathrm{M}$ Bay-11 for $16 \mathrm{~h}$ and examined for the expression of EZH2 mRNA by RT-qPCR using GAPDH mRNA for normalization (left panel). For reporter assay, cells transfected with EZH2 promoter firefly luciferase reporter construct for $24 \mathrm{~h}$, split and treated with $2.5 \mu \mathrm{M}$ Bay-11 at $38 \mathrm{~h}$ post-transfection for another $10 \mathrm{~h}$ were examined for luciferase activities (right panel). In both cases, the levels of untreated cells was set as "1". C, vFLIP and LANA up-regulate the expression of EZH2 protein and mRNA in BOEC cells. Cells transduced with vFLIP (upper and middle panels), LANA (lower panel) or control lentivirus for $48 \mathrm{~h}$ with or without further treatment with $2 \mu \mathrm{M}$ Bay-11 for an additional $24 \mathrm{~h}$ (vFLIP) were examined for the expression of EZH2 protein (vFLIP- and LANA-transduced cells) and mRNA (vFLIP-transduced cells). Expression of vFLIP and LANA was detected by measuring the expression of mRNA (vFLIP) and protein (LANA), respectively. The expression of GAPDH was used for normalization. D, Conditioned medium has no effect on EZH2 expression. Uninfected BOEC cells were treated with conditioned medium from either mock- or KSHV-infected BOEC cells for $24 \mathrm{~h}$, and examined for the expression of EZH2 protein. 
A

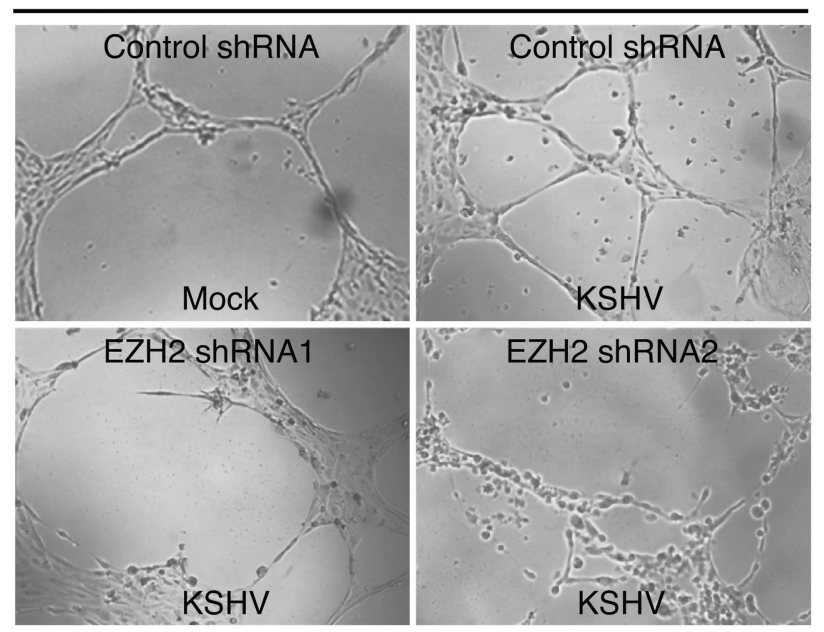

Quantification of tubule length
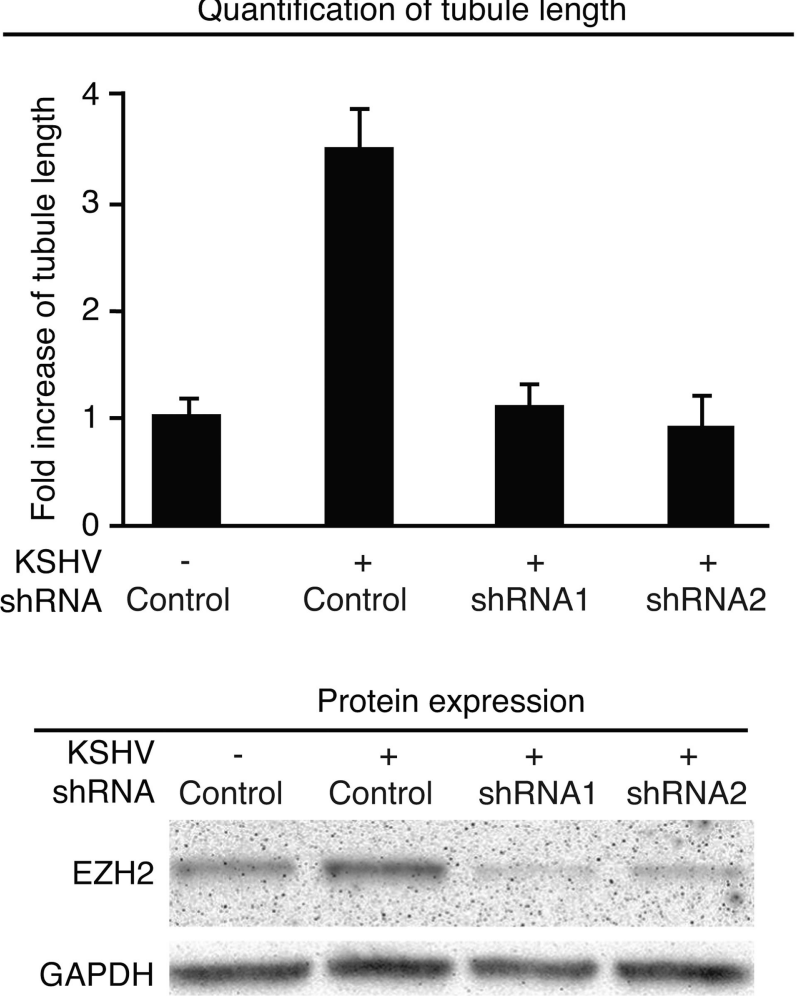

Figure 4.
B

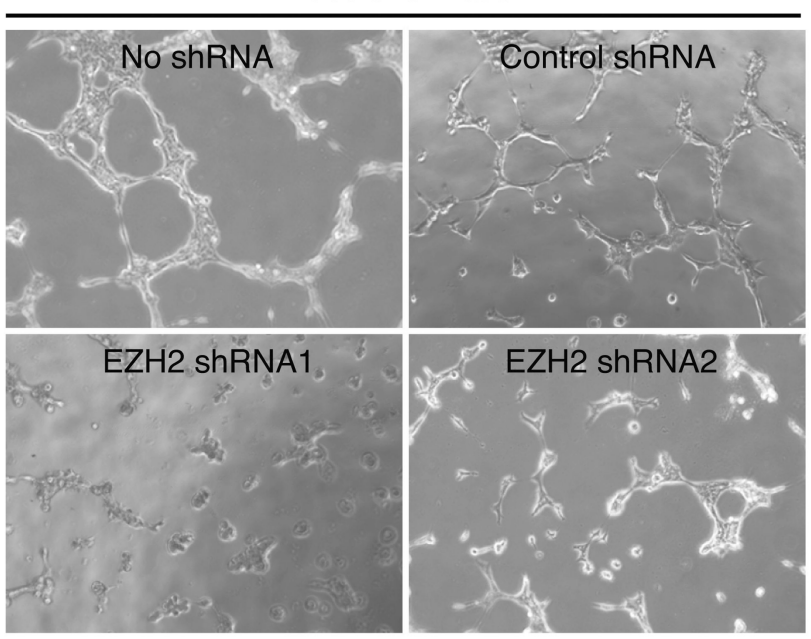

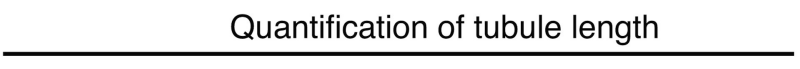
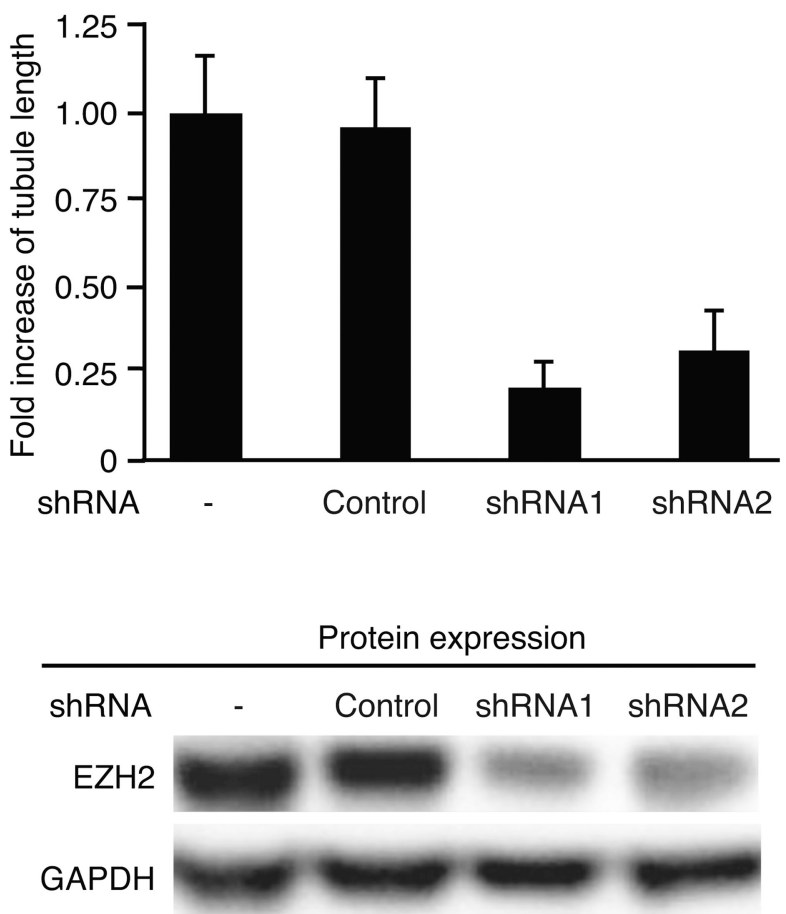

EZH2 mediates KSHV-induced tubule formation in endothelial cells. A and B, Knockdown of EZH2 inhibits tubule formation in KSHV-infected BOEC (A) and SLKp (B) cells. Mockor KSHV-infected BOEC cells were transduced with lentivirus of EZH2 shRNA or control shRNA for 4 days, serum starved for $12 \mathrm{~h}$ and examined for the tubule formation on Matrigel in full medium. Representative images of tubule formation (top panel) were taken at $7 \mathrm{~h}$ post-plating, and quantified for tubule length (middle panel). Cells were also examined for the expression of EZH2 protein at day 4 lentivirus post-transduction (lower 
panel). Experiments with SLKp cells (B) were carried out as the BOEC cells except cells were not subjected to serum starvation before the tubulogenesis assay. 

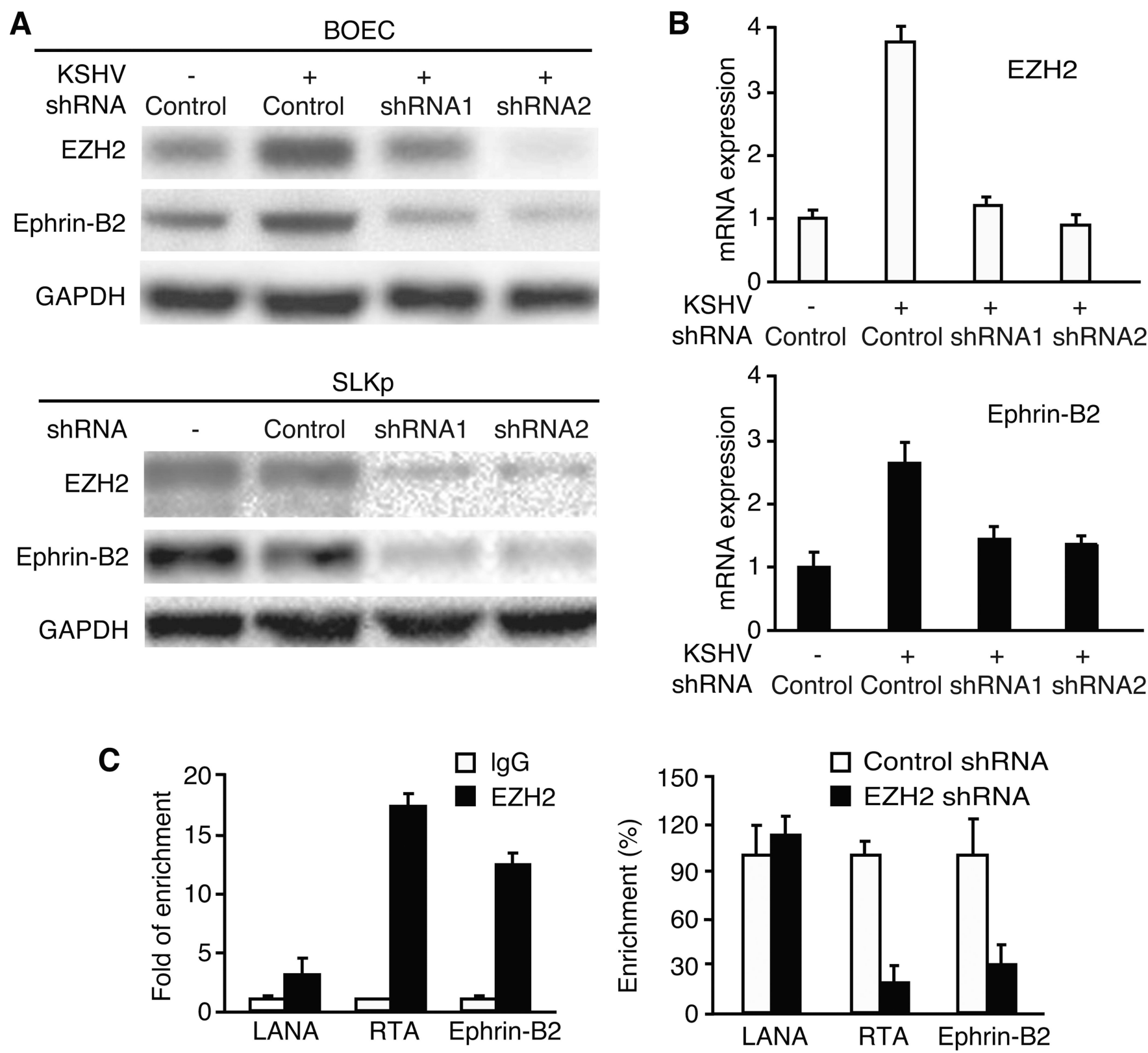

Figure 5.

$\mathrm{EZH} 2$ is required for the expression of Ephrin-B2 in KSHV-infected endothelial cells. A, $\mathrm{EZH} 2$ is required for the expression of Ephrin-B2 protein in BOEC and SLK cells. Mockand KSHV-infected BOEC cells (top panel) and SLKp cells (lower panel) were transduced with lentivirus of EZH2 shRNA or control shRNA for 4 days, and examined for the expression of EZH2 and Ephrin-B2 proteins. B, EZH2 is required for the expression of Ephrin-B2 mRNA in BOEC cells. Mock- and KSHV-infected BOEC cells described in (A) were also examined for the expression of EZH2 and Ephrin-B2 mRNAs. C, EZH2 directly binds to the Ephrin-B2 promoter. Chromatin from SLKp cells with or without transduction with lentivirus of EZH2 shRNA or control shRNA for 4 days were immunoprecipitated with an EZH2 antibody or IgG control. Immunoprecipitated DNA were extracted and examined 
for the presence of Ephrin-B2 promoter DNA by qPCR. RTA and LANA promoters known to have strong and weak EZH2 binding, respectively, were used as controls. Chromatin enrichment by the EZH2 antibody was calculated as the percentage of the immunoprecipitated DNA and compared to IgG precipitated DNA (" 1 " in the left panel). Binding of EZH2 protein to the promoters in cells with shRNA knockdown was compared to those transduced with control shRNA ("100\%" in the right panel). 
A
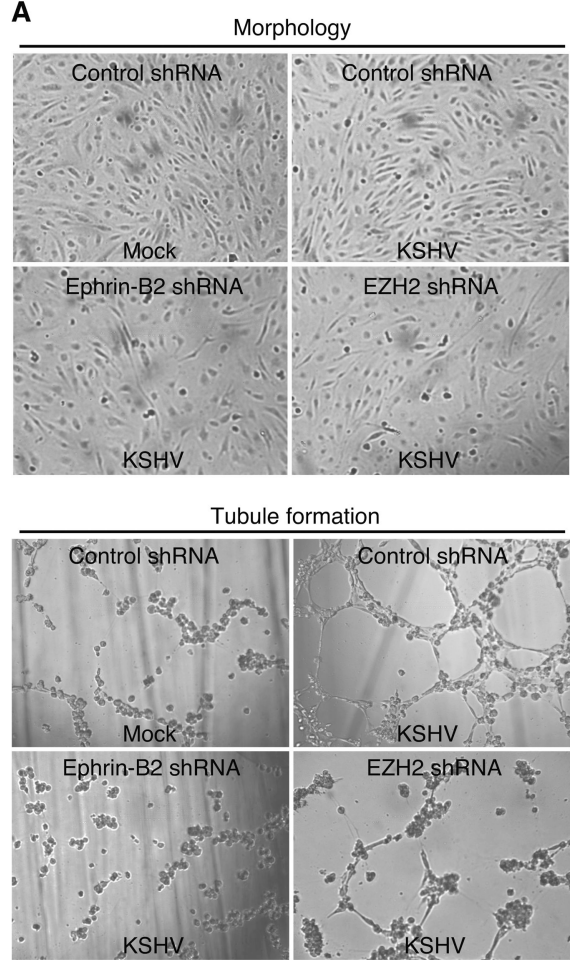

Quantification of tubule length
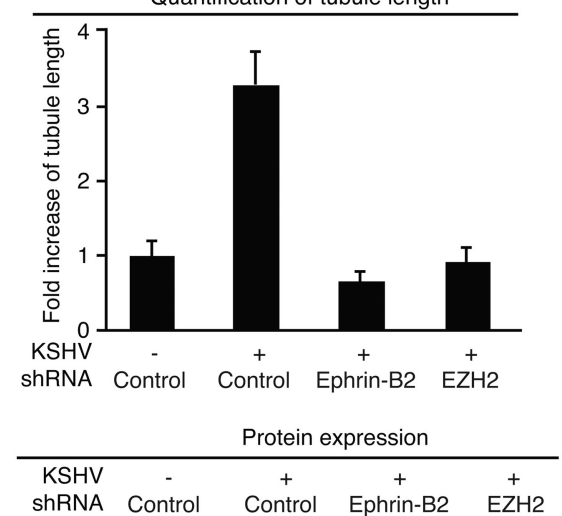

Figure 6.
B
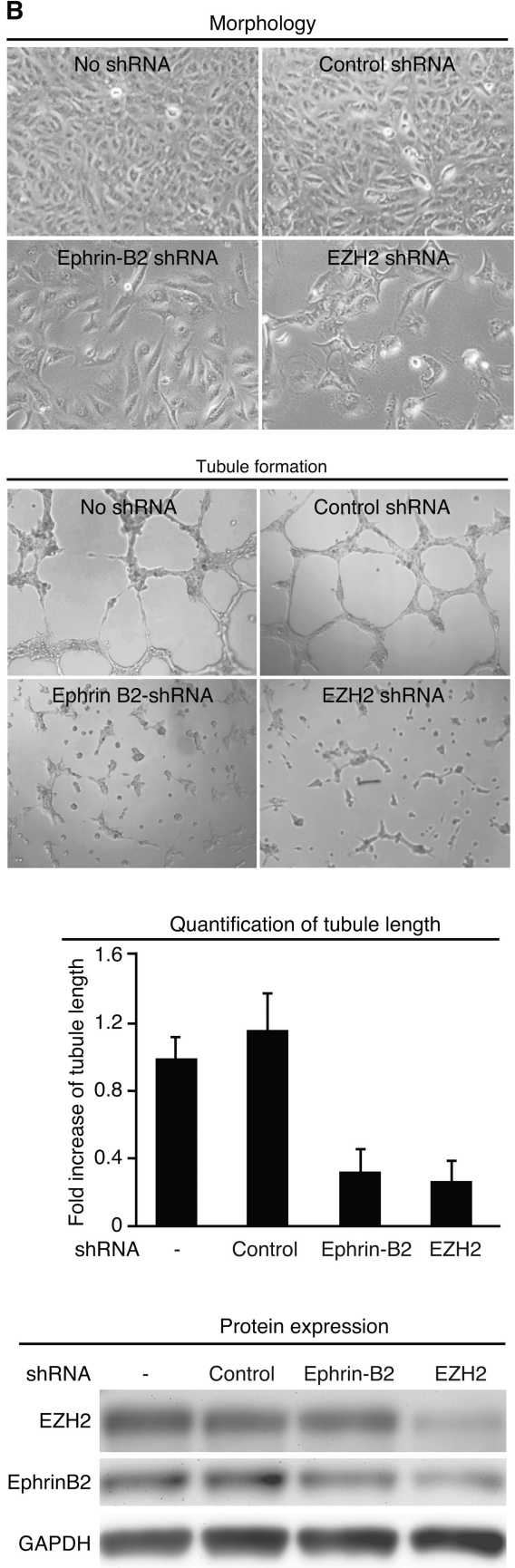

Ephrin-B2 mediates EZH2 enhancement of KSHV-induced tubule formation in endothelial cells. A and B, Knockdown of either Ephrin-B2 or EZH2 inhibits cell growth and tubule formation in KSHV-infected BOEC (A) and SLKp (B) cells. Mock or KSHV-infected BOEC cells were transduced with lentivirus of EZH2 shRNA, 3 pooled Ephrin-B2 shRNAs or control shRNA for 4 days and examined for cell growth by directly counting of cell number on the phase contrast images (upper panel). Transduced cells were also serumstarved for $12 \mathrm{~h}$ and examined for the tubule formation on Matrigel in full medium. 
Representative images of tubule formation (second panel) were taken at $7 \mathrm{~h}$ post-plating and quantified for tubule length (third panel). Cells were examined for the expression of EZH2 and Ephrin-B2 proteins at day 4 lentivirus post-transduction (lower panel). Experiments with SLKp cells were carried out as the BOEC cells except cells were not subjected to serum starvation before the tubulogenesis assay. 


\section{Table 1}

Summary of EZH2 staining results

\begin{tabular}{ll}
\hline Tissue (n) & EZH2-positive tissue, $\mathbf{n}(\boldsymbol{\%})$ \\
\hline Normal tissue (38) & $4(11)$ \\
Lymph node (28) & $1(3.6)$ \\
Skin (5) & $1(20)$ \\
Spleen (2) & $0(0)$ \\
Anus (2) & $1(50)$ \\
Mouth (1) & $1(100)$ \\
\hline KS tissue (173) & $157(91)$ \\
Skin (77) & $75(97)$ \\
Mouth (32) & $27(84)$ \\
Lymph node (25) & $24(96)$ \\
Tonsil/adenoids (10) & $8(80)$ \\
Head/neck (8) & $6(75)$ \\
Rectum (8) & $7(88)$ \\
Lung (5) & $3(60)$ \\
Spleen (2) & $2(100)$ \\
Anus (2) & $2(100)$ \\
Small bow (2) & $1(50)$ \\
Stomach (1) & $1(100)$ \\
Other (1) & $1(100)$ \\
\hline
\end{tabular}

